\title{
Compression of the effect of individual and in group physical exercise on state anxiety in young people
}

\author{
Rasoul Karbalaee Shirifard ${ }^{1}$, Hrant Avanesyan ${ }^{2}$, Habib Honari ${ }^{3}$ and Soghra Ebrahimi Ghavam Abadi ${ }^{4}$ \\ ${ }^{1}$ Philosophy and Psychology Department, Yerevan State University, Armenia \\ ${ }^{2}$ Head of General Psychology Chair, Yerevan State University, Armenia \\ ${ }^{3}$ Physical Education Department, Allameh Tabatabaei University, Republic Islamic of Iran \\ ${ }^{4}$ Educational Psychology Department, Allameh Tabatabaei University, Republic Islamic of Iran \\ 1'rksh50@yahoo.com; ${ }^{2}$ psydep@ysu.am; ${ }^{3}$ Honari_h@yahoo.com; ${ }^{4}$ Qavam2005@yahoo.com
}

\begin{abstract}
We evaluated the impact of in group and individual eight-week exercise intervention on reducing state anxiety in students. Participants ( $M$ age $=20,6 ; N=51$ ) were accidentally assigned to one of three groups: bodily fitness, and volleyball playing and control group. Classes met 1 hour, 3 days per week, for 8 weeks. State Anxiety scale by Spielberger et al. (1970) was administrated to the young people. Results were analyzed by variance analyze and it reveals that a reduction in state anxiety over the intervention. Volleyball participants as team exercise experienced the most benefits. This result reveals that group exercise is more effective than individual exercise in reducing the state anxiety.
\end{abstract}

Keywords: Anxiety, Exercise, Health, Youth,

\section{Introduction}

Anxiety is generally describes human emotions and trait anxiety is constant anxiety during a person's life. New condition can make new anxiety and maybe somebody cannot cope with it. Young people who have fewer experiences in their life and it can increase difficulties for them. When anxiety goes up, the person cannot live normally and he or she thinks what have to do for descending it and coping with it. Psychologists and psychiatrists have various methods of dealing with it.

Anxiety is a generalized mood that can occur without an identifiable triggering stimulus. As such, it is distinguished from fear, which is an appropriate cognitive and emotional response to a perceived threat. Additionally, fear is related to the specific behaviors of escape and avoidance, whereas anxiety is related to situations perceived as uncontrollable or unavoidable (Ohman, 2000). Another view defines anxiety as "a future-oriented mood state in which one is ready or prepared to attempt to cope with upcoming negative events (Barlow \& David, 2002). Anxiety can be either a short term 'state' or a long term "trait." Trait anxiety reflects a stable tendency to respond with state anxiety in the anticipation of threatening situations (Schwarzer, 1997). Early anxiety intervention programs have shown to reduce the number of anxiety disorders among children and youth (Dadds et al., 1997).

Exercise has benefits beyond the physical (Rasoul Karbalaee Shirifard \& Habib Honari, 20012).. Many forms of exercises are currently popular, and the group exercise format has expanded in recent years to include new offerings and to formulate regulated versions of traditional forms of exercise. When thinking of the benefits of exercise, we often think only of the physical and physiological benefits such as increased muscle mass, decreased fat, decreased resting heart rate and/ or decrease blood pressure. In most cases, these benefits are enough to get people started on an exercise program and to keep them involved in regular exercise (Weinberg
\& Gould, 2003). Today it detected that various forms of training offer some benefit, different forms of training provide varying benefits. This study focused on those benefits which are team psychological aspects in nature. Finally, since many of the physical fitness options at fitness and community centers are offered in a group exercise format, beneficial outcomes of exercise for the young people may be related to the social interactions associated with such settings. Physical activity is associated with a range of health benefits, and its absence can have harmful effects on health and well being, increasing the risk for coronary heart disease, diabetes, certain cancers, obesity, hypertension and all cause mortality (CDC 1996). The aim of this study was that, whether team or individual training has an impact on reducing anxiety

\section{Models of qualifier the profit of exercise}

Several models of psychosocial and psychological profit of exercises have been raised and there are many mechanisms by which exercise is thought to influence human health. One of them is Endorphin hypothesis, which states that the endorphin produced by exercise may lead to a change of mood. The influence of acute exercise on psychological well-being, in particular 'euphoria', is caused by the release and subsequent binding of endogenous opiate, these being -endorphins to receptor sites in the brain (Steinberg \& Sykes, 1985). Other psychological theory is Self-esteem; there are models that try to explain the relationship between selfesteem and physical exercises. These models have focused on increasing awareness of the body, strengthen the mind, increase confidence and prosperity, enhance social relationships, reduce anxiety are the benefits of physical exercise. One such model is (Sonstroem, 1978) psychological model for physical activity and another factor is distraction hypothesis. Distraction hypothesis implies man's attention to something other than anxiety, and this anxiety can be reduced. We can find it in conceptualization by Bahrke \& Morgan (1978) it
Sci.Technol.Edu.

CIndian Society for Education and Environment (iSee)
"Group exercise \& state anxiety" http://www.indjst.org
R.K.Shirifard et al. Indian J.Sci.Technol. 
compared the effects on state anxiety of walking on a treadmill, meditating or resting in a comfortable chair. Instructions and methods

With regard to this investigation, young students from 5 different Departments belongs to different Faculty in Allameh Tabatabaee University, participated. Teaching students of primary (1,2 years) base with no previous training, who were accidental and evenly assigned to engage in one of two treatments for 8 weeks form the study cohort. State Anxiety scale (STAl) by Spielberger and a demographic questionnaire were used to 110 students. 51subjects that had the High rates of state anxiety were assigned. Students participated in two groups: experimental and the non experimental group (control). State anxiety scale was used twice: one at the beginning and another at final, after intervention, (pre and post-test performed for test and non experimental groups). Findings were calculated by variance analyze. Experimental groups engaged in training as bodily fitness, and volleyball playing. The findings support for the use of exercises as a strategy for coping with anxiety. Young people for 1 hour three times per week during the eight weeks did exercises. Statistical of descriptive was determined for each group. For testing of the variance analysis, 0.05 significance rate was chosen.

\section{Participants}

Participants were young people (ages 18 to $24 ; \mathrm{M}=$ 20.66, $\mathrm{SD}=1.94$ ) and they were 51 students (intervention group, $n_{-} 32$; control group, $\left.n_{-} 18\right)$. Gender distribution was, Male students constituted $4 \overline{3} .1 \%$ ( $n$ 22) and $56.9 \%(n \ldots 29)$ for female. Marital status was $64.7 \%$ ( $\left.n_{-}{ }_{3} 3\right)$ for singles and $23.5 \%\left(n_{-}{ }_{12}\right)$ for married and a minority of the students reported that they were divorced $11.8 \%$ and $(n+6)$. Occupation distribution was, part-time work students constituted $35.3 \%\left(n_{2} 18\right)$ and $64.7 \%\left(n_{-}\right.$ 33) for no job students. Participants were from 5 collages: Psychology 23.5\% ( $\left.n_{-} 12\right)$, Literature $23.5 \%(n \ldots 12)$, Management $21.6 \%\left(n_{-}-11\right)$ and for Political $15.7 \%\left(n_{-}\right.$ $8)$ and the end was Council $15.7 \%\left(n_{-} 8\right)$. Subjects were 51 individuals and divided in 3groups: Control Group18 persons, Bodily Fitness 17 persons and for Volleyball playing 16 persons.

\section{Instrumentations}

These included a demographic questionnaire, the State Anxiety scale. The principal investigators created a behavioral pre questionnaire to collect demographic information about the participants. The demographic questionnaire includes age, gender, marital status, occupational status, and their collage.

State-Trait Anxiety scale (STAl, Spielberger et al., 1970), is a 40-item scale, which assesses both state (how an individual feels at a particular moment in time) and trait (how an individual generally feels) anxiety. State anxiety is experienced as anxiety that fluctuates over time and arises to a responsive situation. State anxiety is related to a person's learning background. A person may have experienced some anxiety in a situation and that anxiety is transferred to a similar situation. The original State-Trait Anxiety Inventory (STAI) was developed by Spielberger in 1970; the present version of the STAI was revised in 1983.22. The STAI has two parts: the State Anxiety Inventory (SAI) and the Trait Anxiety Inventory (TAl). The former part measures situational anxiety whiles the latter measures baseline anxiety; each part consists of 20 items. These items are rated on a 4-point scale, with a higher score equating to a greater anxiety level. According to studies by Spielberger et al. (1970), the test retest correlation for the TAl is higher than that for the SAI. Despite the fluctuating test-retest correlations of the SAI, which reflect its validity in measuring state anxiety, the internal consistency of the SAI, as measured by the Cronbach's alpha score, has been found to be high. In one case the authenticity, reliability, and validity of the Chinese translation have been tested previously in China and found to have good agreement with the original version. STAI is one of the most frequently used instruments for assessing the psychological benefits of exercise, although certain cautions are warranted, because the STAI has not been validated for exercise purposes (Gauvin \& Spence, 1998). Test-retest of AState is low (ranging from 0.16 to 0.54 ), indicating alterations in psychological state (Spielberger et al., 1970). Internal consistency for the state dimension is reported as 0.82 (Gauvin \& Spence, 1998).

The rationale for choosing each of these interventions was as follows:

Bodily fitness: the fitness intervention was chosen based on the lesson project of university of Allameh Tabatabaei. Each bodily fitness session began with a 10 minute warm-up and ended with a 10 minute cool-down. Therefore, a fitness class which focused on strength and balance activities was implemented as one of the exercise interventions. Title of plane: Bodily fitness, Warm-up:10 minutes, Bodybuilding: 20 minutes, Stationery exercises: 20 minutes, Cold-down: 10, Goal of exercise: ascending of 5 factors of bodily fitness: 1 : speed 2: power 3: resistance 4: agility 5: flexibility.

Volleyball playing group (volleyball class): the Volleyball program was selected because it is a team exercise which is frequently used for colleague's individuals. The Volleyball playing is inexpensive and convenient, and therefore is both accessible and beneficial for almost all colleagues' individuals. The Volleyball playing was a team exercise program, with instructor guidance and support. Individuals assigned to the Volleyball playing intervention were provided with a specific route. Both indoor and outdoor Volleyball playing were available. Participants were encouraged to play for as much of each 1 hour session as possible, for working with everyone, it began with a 10minute warm-up and ended with a 10 minute cool-down but to rest as 5 minutes as needed at the halftime. The instructor also provided guidance about proper playing shoes and other equipment, playing volleyball form, and offered motivation and
Sci.Technol.Edu.

Clndian Society for Education and Environment (iSee)
"Group exercise \& state anxiety" http://www.indjst.org
R.K.Shirifard et al. Indian J.Sci.Technol. 
encouragement to the playing participants. Interaction among the volleyball group members as a whole was fostered. However, interaction between players did occur. A control group (non experimental) intervention was selected as a control without physical activity.

Procedure

Table 1. Participants' $(N=68)$ Demographics

\begin{tabular}{|c|c|c|c|c|c|}
\hline \multicolumn{6}{|c|}{ Statistics } \\
\hline $\mathrm{N}: 51$ & Age & \multirow{2}{*}{ Factor } & \multirow{2}{*}{ Category } & \multirow{2}{*}{$\mathrm{F}$} & \multirow{2}{*}{$\%$} \\
\hline Mean & 20.60 & & & & \\
\hline Median & 20 & \multirow{2}{*}{ Gender } & \multirow{2}{*}{$\begin{array}{l}\text { Female } \\
\text { Male }\end{array}$} & \multirow{2}{*}{$\begin{array}{l}29 \\
22\end{array}$} & \multirow{2}{*}{$\begin{array}{l}56.9 \\
43.1\end{array}$} \\
\hline Mode & 19 & & & & \\
\hline Std. & 194 & \multirow{3}{*}{$\begin{array}{l}\text { Marital } \\
\text { Status }\end{array}$} & \multirow{3}{*}{$\begin{array}{l}\text { Single } \\
\text { Married } \\
\text { Divorced }\end{array}$} & \multirow{3}{*}{$\begin{array}{l}33 \\
12 \\
6 \\
\end{array}$} & \multirow{3}{*}{$\begin{array}{l}67.7 \\
23.5 \\
11.8 \\
\end{array}$} \\
\hline Deviation & 1.94 & & & & \\
\hline Minimum & 18 & & & & \\
\hline \multirow{7}{*}{ Maximum } & \multirow{7}{*}{24} & \multirow{7}{*}{$\begin{array}{l}\text { Occupation } \\
\text { status } \\
\text { Collage }\end{array}$} & \multirow{7}{*}{$\begin{array}{l}\text { Part-time } \\
\text { Work } \\
\text { None job } \\
\text { Psychology } \\
\text { Literature } \\
\text { Management } \\
\text { Political } \\
\text { Council }\end{array}$} & 18 & 35.3 \\
\hline & & & & 33 & 64.7 \\
\hline & & & & 12 & 23.5 \\
\hline & & & & 12 & 23.5 \\
\hline & & & & 11 & 21.6 \\
\hline & & & & $\begin{array}{l}8 \\
8\end{array}$ & 15.7 \\
\hline & & & & & \\
\hline
\end{tabular}

This research project provided 1 hour sessions, three times per week, for eight weeks. The subjects were briefed on the importance of attending all exercise sessions. In bodily fitness group asked not to discuss the intervention with each other, in order to prevent the effects of social influence but in Volleyball group were also asked to discuss the intervention with each other, in order ascend the effects of social influence. Each fitness intervention lasted 1 hour, but participants were encouraged and reminded to rest as needed during each exercise session. Assessments were conducted pre-intervention, with the participants filling out the entire tests, the state measures (state STAI). Demographic data (including age,

\begin{tabular}{|l|}
\hline \multicolumn{1}{|c|}{$\begin{array}{c}\text { Research } \\
\text { Group }\end{array}$} \\
\hline \\
\hline Control Group \\
\hline Exercise Group \\
\hline TOTAL \\
the end of eight \\
\begin{tabular}{|l|}
\hline$\%$ \\
\hline 35.3 \\
\hline 33.3 \\
\hline 31.4 \\
\hline 100.0 \\
\hline
\end{tabular}
\end{tabular}
gender, occupational status, marital status, and current collage) were collected (Table 1-4). At the end of eight

Table 2. Dispersion of 3 groups

\begin{tabular}{|l|l|l|}
\hline Groups & $\mathrm{F}$ & $\%$ \\
\hline Control group & 18 & 35.3 \\
\hline Bodily fitness & 17 & 33.3 \\
\hline Volleyball & 16 & 31.4 \\
\hline Total & 51 & 100.0 \\
\hline
\end{tabular}

weeks of intervention, assessment was conducted, with individuals completing the entire of measures (state STAI).

\section{Data Analysis}

Data were analyzed with SPSS software. Descriptive statistics were calculated for the demographic variables. Differences between groups (Intervention for 51 young people by group and by pre test) were calculated at baseline, using one-way analysis of variance. Repeated measures analysis of variance assessed differences in the degree of change in study variables from pre to post intervention.

For the first hypothesis, which cited that no significant differences among mean rate for participants in the two

Table 3. The dispersion of collages students (STAI)

\begin{tabular}{|l|c|c|}
\hline \multicolumn{1}{|c|}{ Department } & Total Student & Ratio (\%) \\
\hline Psychology & 12 & 23.5 \\
\hline Literature & 12 & 23.5 \\
\hline Management & 11 & 21.6 \\
\hline Political & 8 & 15.7 \\
\hline Council & 8 & 15.7 \\
\hline Total & 51 & 100.0 \\
\hline
\end{tabular}

exercise interventions and one control group would be observed in beginning information, was tested using an analysis of variance for state anxiety levels in beginning measures. Then for the second hypothesis, which cited that all exercise interventions would result reduced state anxiety levels over the course of the 8-week intervention, was tested using an Analysis of variance for dependent variable. But for the third hypothesis, which stated that team exercise interventions would show mean different in progressively reduced state anxiety levels than individual intervention, was tested using an Analysis of variance for dependent variable.

\section{Results}

Fig. 1 depicts the box plot for scores of three groups. According to the results of pretest and post-test non experimental group, there is no significant difference in the average two-test, Results showed no change in both

Table 4. The dispersion of research group for gender

\begin{tabular}{|c|c|c|c|c|c|}
\hline \multicolumn{2}{|c|}{ Female } & \multicolumn{2}{c|}{ Male } & \multicolumn{2}{c|}{ Total } \\
\hline Number & $\%$ & Number & $\%$ & Number & $\%$ \\
\hline 10 & 55.6 & 8 & 44.4 & 18 & 100,0 \\
\hline 19 & 57.6 & 14 & 42.4 & 33 & 100,0 \\
\hline & & & & 51 & 100.0 \\
\hline
\end{tabular}

pre and post-test anxiety rates. For non experimental group, in the first test the standard deviation is 2.51 and in Post-test standard deviation are 2.28. Looking at the average of two test for none experimental group (52.77 pretest and 52.55 post-test), we find a close similarity in the two test. Within- subject's factors, two tests (pre and post-test) informed as Dependent variable (Table 5).

Table 5. Between-Subjects Factors for 3 group

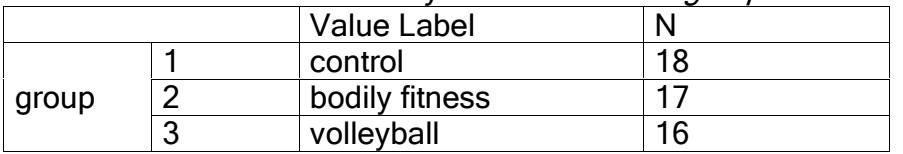

Table 5 represents Between-Subjects Factors for 3 group (control, bodily fitness and volleyball).

Table 5. Dependent variable

\begin{tabular}{|l|l|}
\hline Anxiety & Dependent Variable \\
\hline 1 & score1 \\
2 & score2 \\
\hline
\end{tabular}


Table 6. Mauchly's Test of Sphericitya

\begin{tabular}{|c|c|c|c|c|c|c|c|}
\hline \multirow{2}{*}{$\begin{array}{c}\text { Within } \\
\text { Subjects } \\
\text { Effect }\end{array}$} & \multirow{2}{*}{$\begin{array}{c}\text { Mauchly's } \\
\text { W }\end{array}$} & \multirow{2}{*}{$\begin{array}{l}\text { Approx. Chi- } \\
\text { Square }\end{array}$} & \multirow[b]{2}{*}{$d f$} & \multirow[b]{2}{*}{ Sig. } & \multicolumn{3}{|c|}{ Epsilon $^{b}$} \\
\hline & & & & & $\begin{array}{c}\text { Greenhouse } \\
\text {-Geisser }\end{array}$ & $\begin{array}{l}\text { Huynh- } \\
\text { Feldt }\end{array}$ & Lower-bound \\
\hline Anxiety & 1.000 & 0.000 & 0 & & 1.000 & 1.000 & 1.000 \\
\hline
\end{tabular}

The second hypothesis cited that all exercise interventions would result in progressively reduced state anxiety end of intervention. Findings show that there is significant difference between pre and post-test for experimental groups (bodily fitness). The hypothesis was tested using a Repeated Measures (RM) Analysis of Covariance (ANCOVA) for dependent variable anxiety using the pretest score as a Covariate (Table 6).

Time (including the two data points) was within repeated factor, while treatment (2 levels and a control) was the between-subjects factor. Stat anxiety rates descended from pre test to post-test in experimental groups (bodily fitness).

Table 7 shows ANOVA for pre and post test between and within groups. Table 8 provides Descriptive Statistics for 3 groups in pre and post test (state anxiety).

There was 55.05 for first mean in pre test and 46.23 for second mean in post- test for experimental group (bodily fitness). For bodily fitness group, in the first test the standard deviation is 5.69 and in Post-test standard deviation are 5.76. With notice to deceasing in means of two tests, we observed descending in stat anxiety rate for

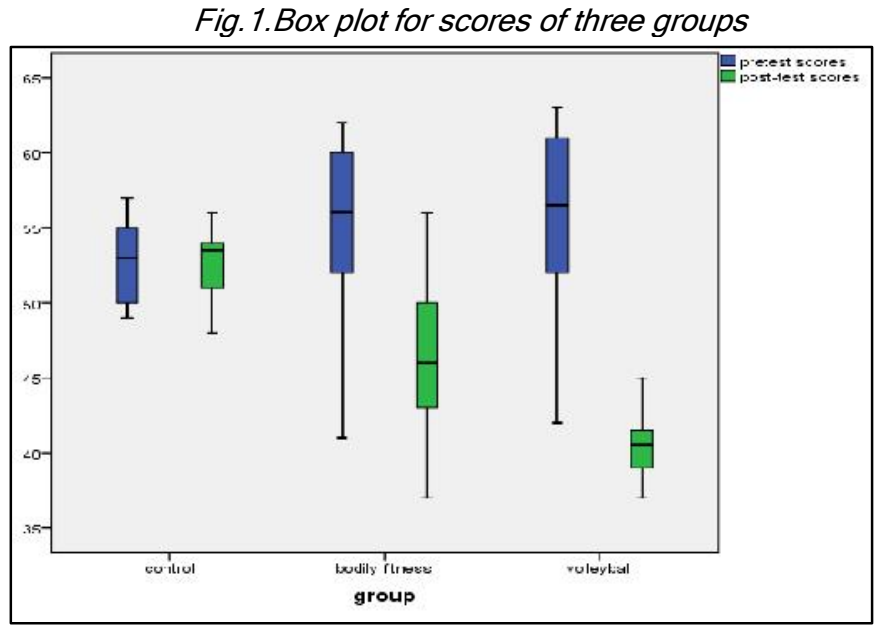

Vol. 5 No. 4 (Apr 2012)

ISSN: 0974- 6846 significant, $F(2,48)=122.906$
$(P<0.05)$. It is meaningless to assume that it has emerged reduction in stat anxiety itself. Initial analysis of findings of the experimental group (volleyball), showed reduced state anxiety in experimental group during (in pre test and post-test) the intervention period. Differences were obtained, the mean score of 55.93 for the first evaluation and the average score of 40.50 for the second evaluation, in group exercise (volleyball). For volleyball group, in the first test the standard deviation is 6.19 and in Post-test standard deviation is 2.22 . With descending the average rate of the first evaluation and second evaluation, anxiety was reduced.

Table 8. Descriptive Statistics for 3 groups in pre and post test (state anxiety)

\begin{tabular}{|l|l|c|c|c|}
\hline & \multicolumn{1}{|c|}{ Group } & Mean & Std. Deviation & $\mathrm{N}$ \\
pretest & control & 52.7778 & 2.51011 & 18 \\
scores & bodily fitness & 55.0588 & 5.69507 & 17 \\
& volleyball & 55.9375 & 6.19106 & 16 \\
& Total & 54.5294 & 5.08469 & 51 \\
& control & 52.5556 & 2.28092 & 18 \\
post-test & bodily fitness & 46.2353 & 5.76118 & 17 \\
scores & volleyball & 40.5000 & 2.22111 & 16 \\
& Total & 46.6667 & 6.21182 & 51 \\
\hline
\end{tabular}

There was a significant difference in state anxiety levels of students in the experimental group (volleyball), and this difference was significant between the first assessment and second assessment, $F(2,48)=$ 122.906, $(\mathrm{P}<0.05)$. It is meaningless to assume that it has emerged reduction in state anxiety itself and suddenly. With notice to findings, we observed that Groups were equally in beginning, one hypothesis in the beginning supposed that non-significant differences would emerge among average rate for the two interventions and the non experimental group for state anxiety in the beginning, as a result of randomized found to the three groups. The hypothesis was tested using a multivariate analysis of variance for, state anxiety measures in the beginning. kurtosis of the pre test for total groups, was .052. And

\begin{tabular}{|c|c|c|c|c|c|c|c|}
\hline & & & $\begin{array}{c}\text { Sum of } \\
\text { Squares }\end{array}$ & df & $\begin{array}{l}\text { Mean } \\
\text { Square }\end{array}$ & $\mathrm{F}$ & Sig. \\
\hline \multirow{3}{*}{ pretest scores * group } & Between Groups & (Combined) & 91.716 & 2 & 45.858 & 1.833 & 0.171 \\
\hline & Within Groups & & 1200.990 & 48 & 25.021 & & \\
\hline & Total & & 1292.706 & 50 & & & \\
\hline \multirow{3}{*}{ post-test scores * group } & Between Groups & (Combined) & 1235.830 & 2 & 617.915 & 42.768 & 0.000 \\
\hline & Within Groups & & 693.503 & 48 & 14.448 & & \\
\hline & Total & & 1929.333 & 50 & & & \\
\hline \multirow{3}{*}{ Mean case * group } & Between Groups & (Combined) & 167.643 & 2 & 83.822 & 6.528 & 0.003 \\
\hline & Within Groups & & 616.367 & 48 & 12.841 & & \\
\hline & Total & & 784.010 & 50 & & & \\
\hline
\end{tabular}

Sci.Technol.Edu.

CIndian Society for Education and Environment (iSee)
"Group exercise \& state anxiety" http://www.indjst.org
R.K.Shirifard et al. Indian J.Sci.Technol. 
Table 9. Tests of within-subjects effects for state anxiety

\begin{tabular}{|l|l|l|l|l|l|l|}
\hline \multicolumn{2}{|c|}{ Source } & $\begin{array}{l}\text { Type III Sum } \\
\text { of Squares }\end{array}$ & \multicolumn{1}{|c|}{ df } & Mean Square & \multicolumn{1}{|c|}{ F } & Sig. \\
\hline Anxiety & $\begin{array}{l}\text { Sphericity } \\
\text { Assumed }\end{array}$ & 1694.462 & 1 & 1694.462 & 122.906 & .000 \\
\hline Anxiety ${ }^{*}$ group & $\begin{array}{l}\text { Sphericity } \\
\text { Assumed }\end{array}$ & 992.260 & 2 & 496.130 & 35.986 & .000 \\
\hline Error(Anxiety) & $\begin{array}{l}\text { Sphericity } \\
\text { Assumed }\end{array}$ & 661.760 & 48 & 13.787 & & \\
\hline
\end{tabular}

Vol. 5 No. 4 (Apr 2012)

ISSN: 0974- 6846

kurtosis of the pre test for total groups was -1.47 . Box's Test of Equality of Covariance Matrices indicated that the observed covariance matrices of the dependent variables were equal across groups. Box's $M=32.421, F(15$, $6888.562)=1.09, p<0.05$. Levene's test of equality of variances showed non-significant $(p<.05)$ differences among the three groups' variances on each of the three pretest scores, showing that variances were same. Then, the information appears to meet the assumptions for multivariate analysis. So, randomization resulted in equality of means across groups in beginning. In the end hypothesis, because inspection of the comparisons across groups for each dependent did reveal some differences, for anxiety (state), two the group's differences resulted in a significant $(p<.05)$ affect, $F$ (2.48)=6.528, $P<0.05$. The LSD post-hoc contrast indicated significant $(p<0.05)$ differences between the bodily fitness with volleyball group means (Table 10).

At the end of result one diagram of estimated marginal means of measures showed difference between three groups and volleyball affected more than other group Fig.2.

Table 10. Tests of Between-Subjects Effects for experimental groups and control group

\begin{tabular}{|l|l|l|l|l|r|}
\hline \multicolumn{1}{|c|}{ Source } & $\begin{array}{c}\text { Type III Sum of } \\
\text { Squares }\end{array}$ & \multicolumn{1}{c|}{ df } & \multicolumn{1}{c|}{$\begin{array}{c}\text { Mean } \\
\text { Square }\end{array}$} & \multicolumn{1}{c|}{ F } & Sig. \\
\hline Intercept & 259636.023 & 1 & 259636.023 & 10109.671 & 0.000 \\
\hline group & 335.286 & 2 & 167.643 & 6.528 & 0.003 \\
\hline Error & 1232.733 & 48 & 25.682 & & \\
\hline
\end{tabular}

Fig.2. Marginal means of measures among the 3 groups

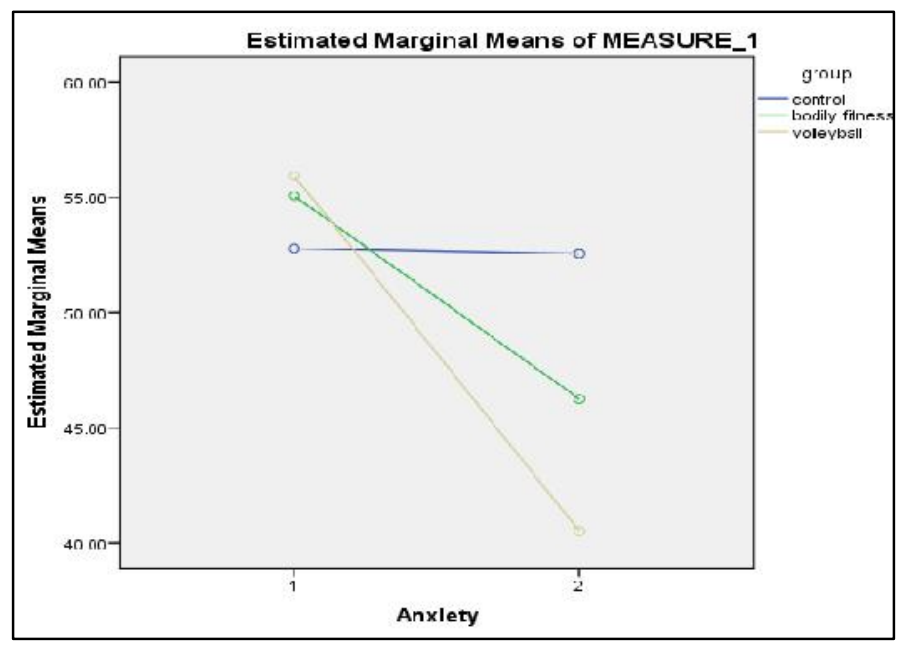

anxiety than non experimenta hypotheses showed serious different. And the third hypotheses showed serious different of mean between volleyball playing and bodily fitness. It was proposed that all two exercise interventions would show a stronger effect over the course of the eight weeks than the non experimental group. This hypothesis was confirmed for anxiety (state). Post-hoc analysis revealed a significant contrast between the volleyball group and the bodily fitness group. At pretest there were no overall differences between groups. In contrast, at the end of the intervention, there were significant group effects for anxiety (state). Only significant post-hoc comparison was for the time by group interaction effect, for the contrast between the volleyball group and the control group. The volleyball playing group's mean was 3.6 rates lower than the non experimental group. All two had significant group effects, and in each case, volleyball had the lowest rate of other group, indicating less anxiety (state) therefore greater mental health. Post-hoc analysis revealed that volleyball had lower means than of the other group. These findings indicate that the volleyball intervention was in some way different than the other exercise group. However, although participants were instructed to set their own comfortable volleyball playing, they tended to exhibit a preference to volleyball playing as a team. If the instructor's volleyball experience did indeed affect experimental outcomes, then it would be difficult to remove this confounding variable. Perhaps, then, there is something inherently different in the nature of volleyball which made it more effective than the other exercise interventions. In one report it found that Effects of exercise programs included improved body image, feelings of mastery brought about by the completion of a physically demanding program, and a variety of group dynamic effects (Norris et al., 1992) And in other report it discovered that Benefits of an exercise program may be attributable, in part, to the social support aspects of the program. (Babyak et al., 2000).Then team physical exercise can be better than individual physical exercise. Life circumstances, one variable which the study was unable to control were the life circumstances of study participants. Because the significant effects of exercise are small, the potential for exercise to make a difference in an individual's psychological well-being is limited.

Conclusions

Of course, if this study will be conducted with larger groups, it will explore more robust statistical results. Post-
Sci.Technol.Edu.

(CIndian Society for Education and Environment (iSee)
"Group exercise \& state anxiety" http://www.indjst.org
R.K.Shirifard et al. Indian J.Sci.Technol. 
hoc analysis did indicate some differences between groups, and it may be that the volleyball intervention was inherently different from the other exercise formats. Team action is often shown better results. Research about human social activity, makes clear the broader dimensions. However, recent research results should be confirmed with further investigation and follow-up and various age groups should be investigated. Character is different from other people, in choosing the type of training, should be notify to personal characteristics and interests also be notify to the facilities and capabilities. Finally, the instructor variable was identified as a critical component of the volleyball playing. This supports previous research, which emphasized the importance of social interaction and instructor leadership as components of effective exercise programs. Coach ability is very important. Future research studies are needed in order to fully understand the impact of the instructor on participants.

\section{References}

1. Bahrke MS and Morgan WP (1978) Anxiety reduction following exercise and meditation. Cognitive Therapy \& Res. 2, 323-333.

2. Babyak M, Blumenthal JA, Herman S, Khatri $P$, Doraiswamy M, Moore K, Craighead E, Baldewicz TT and Krishnan R (2000) Exercise treatment for major depression: Maintenance of therapeutic benefit at 10 Months. Psychosomatic Med. 62(5), 633-638.

3. Barlow and David H (2002) Unraveling the mysteries of anxiety and its disorders from the perspective of emotion theory. Am. Psychologist. 55(11), 1247-63.

4. CDC (1996) Physical activity and health: a report of the surgeon general. US Department of Health and Human Services. National Center for Chronic Disease Prevention and Health Promotion, Atlanta.

5. Dadds MR, Spence S, Holland D, Barrett PM and Laurens K (1997) Prevention and early intervention for anxiety disorders: A controlled trial. J. Consulting \& Clinical Psychol. 65, 627-635.

6. Gauvin L and Spence JC (1998) Measurement of exercise-induced changes in feeling states, affect, mood, and emotions. In: Advances in sport and exercise psychology measurement. Duda JL (Ed.), Morganstown (WV): Fitness Information Technology. pp: 325-336.

7. Ohman A (2000) Fear and anxiety: Evolutionary, cognitive, and clinical perspectives. In: Handbook of emotions. Lewis M \& Haviland-Jones JM (Eds.). The Guilford Press, NY.pp: 573-593.

8. Schwarzer R (1997) Anxiety. Archived from the original on 2007-09-20. http://www.macses.ucsf.edu/Research/

Psychosocial/notebook/anxiety.html. Retrieved 200801-12.

9. Sonstroem RJ (1978) Physical estimation and attraction scales: rationale and research. Med. \& Sci. in Sports. 10, 97-102.
Vol. 5 No. 4 (Apr 2012)

ISSN: 0974- 6846

10.Spielberger CD, Gorsuch RL and Lushene RE (1970) STAI manual for the State-Trait Anxiety Inventory ("Self-Evaluation Questionnaire. Consulting Psychologists Press, Inc.

11.Steinberg $H$ and Sykes EA (1985) Introduction to symposium on endorphins and behavioural processes: a review of literature on endorphins and exercise. Pharm. Biochem \& Behaviour. 23, 857-862.

12. Weinberg R and Gould D (2003) Foundations of sport and exercise psychology. Champaign, IL: Human Kinetics

13. Rasoul Karbalaee Shirifard and Habib Honari (2012) Two exercises as trait anxiety mitigating factors. Indian J.Sci. Technol. 5 (4). 